\title{
Determinants of the electronic distribution of services to tourism organizations in the Kingdom of
} Saudi Arabia

\author{
Nabil Mohemmed Al-Hazmi ${ }^{{ }^{*}}$
}

${ }^{a}$ Associate Professor of Marketing, Department of Marketing, College of Business Administration Prince Sattam bin Abdulaziz University-Kingdom of Saudi Arabia

${ }^{b}$ Associate Professor of Marketing, College of Administrative Sciences, Taiz University, Yemen

\section{H R O N I C L E}

\section{Article history:}

Received: September 20, 2020

Received in revised format:

October 102020

Accepted: October 16, 2020

Available online:

October 16, 2020

Keywords:

Electronic Distribution

Distribution channels

Tourism Organizations

Tourism Services

\section{A B S T R A C T}

This study aims to determine the determinants of the electronic distribution of services for tourism and travel organizations in the Kingdom of Saudi Arabia. The study uses some descriptive analytical approach in achieving its goals and testing its hypotheses. The study found that there are a set of determinants that stand for the distribution of services of tourist organizations, the most important of which is the weakness of communication and software networks as well as the lack of qualified human resources to manage distribution channels. The study recommends the need to develop communication networks and train human resources to manage electronic distribution channels.

\section{Introduction}

Each single producer of a good or a service seeks to find a means connection with all marketing institutions to help him distribute his products, and to achieve his goals. These marketing institutions are called distribution outlets which are a group of organizational units through which goods are marketed. The decisions, regarding the management of distribution channels (outlets), are the main pillar of the distribution strategy. As the proper selection of the outlet members, developing relationships with them, and evaluating their performance, generally, determines the extent of the company's success in achieving spatial benefit and providing markets with products. The producer must make decisions regarding the management of distribution outlets in the following aspects: determining the methods and policies used for distribution (direct distribution - indirect distribution), determining the required distribution intensity, selecting intermediaries according to certain criteria (market coverage - control - cost), developing the relationships with distributors and evaluating the efficiency of distributors' performance. As it is well known, there are different types of distribution outlets between retail stores and wholesale stores. They differ among themselves between the quality of services they provide and the costs associated with them. The producing facility must determine the type of intermediaries who distribute its products among the available intermediaries. It must be determined that should the distribution be heavy so that the number of distributors is huge in each region, or is it selective where the monopoly of a distribution agent should be avoided, or is it limited to deal with a single distribution outlet? Each of the different distribution policies has a comparative advantage, for example, heavy distribution leads to a wider spread. While selective distribution ensures a better choice for distributors. In a limited distribution, the cost is lower. On the other hand, in each of the previous policies, there are weaknesses. The intense distribution is characterized with the defects of the high cost. While the strength of weak selective policy highlights the difficulty of obtaining a competitive position in different markets. In the case of a limited distribution, there are major risks in dealing with a single distributor. Therefore, the most * Corresponding author.

E-mail address: n.alhazmi@psau.edu.sa (N. M. Al-Hazmi) 
suitable distribution outlets for the product to be distributed in the market should be identified by measuring the strengths and weaknesses when it is distributed using each of the previous policies. As the modern era witnessed a revolution in the field of technology and the internet, and these developments became one of its characteristics, and these developments were not limited to an economic sector without the other, and the tourism sector in the Kingdom of Saudi Arabia was affected by these accelerating technological developments, which affected the nature of the tourism product and in the processes of its presentation and distribution as well. Perhaps this is due to the rapid spread of these technological developments and to their low cost, but the provision of services by organizations through these outlets puts them in front of major challenges and determinants ; one of the most important is the intense competition in the travel and tourism market, as it is easy for customers to move from one website to another for travel and tourism organizations spread across the internet with easiness and speed. Whereas the new technology contributes to enhance the competitiveness of tourism organizations by opening new horizons for distributing their services. Therefore, travel and tourism organizations, in the Kingdom of Saudi Arabia in general and in the Al-Kharj region in particular must determine the factors affecting the use of these outlets and work to raise the capability to benefit from the electronic distribution outlets and to enhance and develop the competitiveness of travel and tourism organizations in Al-Kharj Governorate.

Despite the tremendous progress in information technology and communications globally and locally and its use in the distribution of products and services, including tourism services, the travel and tourism organizations in Al-Kharj did not keep pace with these tremendous developments, which weakened their capability to compete locally and at the Kingdom level and did not make use of the tremendous advantages provided by the developments in the information and communications sector, as the problem of the study is to identify the factors and reasons that led to the lack of full use of the electronic distribution outlets for travel and tourism organizations in Al-Kharj Governorate in the Kingdom of Saudi Arabia. This study seeks to achieve the following objectives:

- Studying and determining the factors that limit the capability of travel and tourism organizations in the Kingdom of Saudi Arabia to distribute their services electronically,

- Providing studies and solutions for the problems of travel and tourism organizations and overcoming the difficulties they face in order to develop their operations and distribution in distributing their products and services internally and externally,

- Helping to develop the competitiveness of travel and tourism organizations in Al-Kharj Governorate in particular and the Kingdom of Saudi Arabia in general.

\section{The proposed study}

This study seeks to test the following hypotheses:

- There is a statistically significant relationship at the level of significance $(\alpha \leq 0.05)$ between the laws and regulations which govern travel and tourism organizations and the electronic distribution outlets for tourism services.

- There is a statistically significant relationship at the level of significance $(\alpha \leq 0.05)$ between central planning and decisionmaking in travel and tourism organizations and electronic distribution outlets for tourism services.

- There is a statistically significant relationship at the level of significance $(\alpha \leq 0.05)$ between interest in research and development in travel and tourism organizations and electronic distribution outlets for tourism services.

- There is a statistically significant relationship at the level of significance $(\alpha \leq 0.05)$ between the financial capabilities of travel and tourism organizations and the electronic distribution outlets for tourism services.

- There is a statistically significant relationship at the level of significance $(\alpha \leq 0.05)$ between the human experiences required for electronic distribution management in travel and tourism organizations and electronic distribution outlets for tourism services.

- There is a statistically significant relationship at the level of significance $(\alpha \leq 0.05)$ between the available software in travel and tourism organizations and the electronic distribution outlets for tourism services.

- There is a statistically significant relationship at the level of significance $(\alpha \leq 0.05)$ between the performance of electronic communication networks in travel and tourism organizations and the electronic distribution outlets for tourism services.

- There is a statistically significant relationship at the level of significance $(\alpha \leq 0.05)$ between the risks of the electronic distribution of travel and tourism organizations and the electronic distribution outlets of tourism services.

- There is a statistically significant relationship at the level of significance $(\alpha \leq 0.05)$ between the customers' awareness of travel and tourism organizations on the importance of electronic distribution outlets and electronic distribution outlets for tourism services.

The importance of this study is represented by the following points:

- The intense competition for tourism and travel organizations, whether at the governorate level or in the Kingdom of Saudi Arabia in general.

- Technical developments in the field of communications and the internet, which opened new horizons and new ways for travel and tourism organizations to distribute and deliver their services to their customers at anytime and anywhere. 
- The study represents the first study prepared in this field (travel and tourism) dealing with the determinants, which stand in front of distributing its services electronically.

The study population was represented by travel and tourism companies and organizations in Al-Kharj Governorate in the Kingdom of Saudi Arabia, and the sample was randomly selected. (30) individuals were selected from the study population, and the study sample was distributed among travel and tourism organizations as follows:

Table 1

Distribution of the study sample to travel and tourism organizations.

\begin{tabular}{llll}
\hline N. & Travel and tourism organizations & Sample size & \\
\hline 1 & Travel and tourism agencies & 13 & The ratio $100 \%$ \\
2 & Hotels & 7 & 23 \\
3 & Restaurants & 10 & 24 \\
Total & & 30 & $100 \%$ \\
\hline
\end{tabular}

A questionnaire was designed to collect data on the factors that limit travel and tourism organizations' use of electronic distribution outlets by relying on the Likert five-point scale where one is for strongly disagree and five represents strongly agree. In order to achieve the objectives of this study, it was relied on the descriptive analytical approach, where the literature and studies which were written in the field of electronic distribution of travel and tourism services were reviewed. A questionnaire was designed to identify and determine the factors which limit the use of electronic distribution outlets for travel and tourism products in Al-Kharj Governorate. Table 2 identifies the study variables, in which, we find that this dependent variable is represented by the use of electronic distribution outlets by travel and tourism organizations in Al-Kharj Governorate and 9 independent variables which are represented by the factors which limit the use of electronic distribution.

Table 2

The summary of the independent variables and dependent variable

Independent variables influencing the use of electronic distribution outlets in the distribution of travel and tourism services

1 The bylaws and regulations governing travel and tourism organizations

2 Centralized management in planning and decision-making

3 Weak interest in research and development in travel and tourism organizations

4 Poor financial capabilities

5 Lack of human expertise to manage electronic distribution outlets

6 Lack of software necessary for the work of electronic distribution outlets

7 Poor performance of the communications network

8 The expected risks resulted by the use of the electronic distribution

9 Poor customers' awareness of the importance of electronic distribution outlets

Dependent variable: Using electronic distribution outlets in travel and tourism organizations

laws and regulations

Centralized planning and decision-making

Weak interest in research

lack of financial

Human experiences

lack of software packages

Poor network

Expected risk

Poor customer awareness

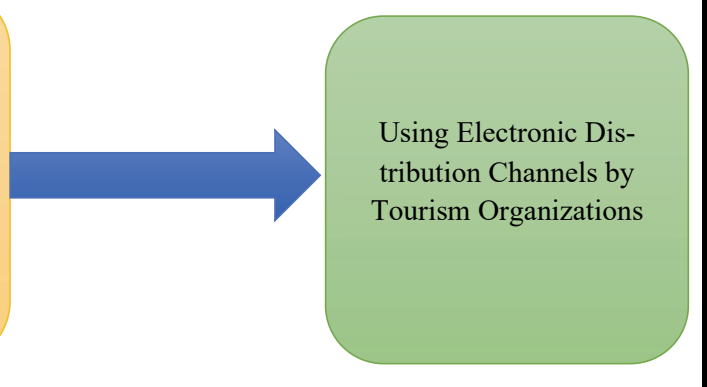

Fig. 1. Study model

There are not many studies that dealt with the issue of distribution of services distribution determinants and less than that, the studies which dealt with the distribution of tourism services (transport and travel services). There are no studies at all on the subject of distribution of services of travel and tourism organizations in the Kingdom of Saudi Arabia. There are some studies that dealt with the travel and tourism sector in general and the electronic distribution of products in other productive sectors; including:

Al-Hazmi (2020) examined the distribution of tourism services through electronic distribution outlets for tourism organizations in Al-Kharj Governorate. The study reached a set of results and recommendations, the most important of which is the necessity of working on the use of electronic distribution methods because of the wide spread of organizations and thus increasing profits. While the study by AL-Hazmi and Hassan (2020) confirmed the existence of a set of determinants and limitations that prevent the marketing of tourism organizations services in the Kingdom of Saudi Arabia and negatively affect the customers' awareness of the nature of the service provided, where it is distributed and the mechanism to access to it. Al- 
Hazmi (2020c) study emphasized on the importance of using the appropriate strategy in marketing the services of tourism organizations and emphasized on the necessity of using the distribution strategy that ensures the delivery of tourism services in the correct and appropriate way for customers and works to achieve the best results for tourist organizations in Al-Kharj Governorate. AL-Hazmi and Alkhateeb (2020). emphasized on the dimensions of the quality of tourism services in a way that guarantees the delivery of these services to the beneficiaries at the price, quality and appropriate place through the use of distribution methods capable of achieving the beneficiaries' satisfaction towards these services and enhances the positive image in their mind of tourism services in Al-Kharj Governorate. While the study by Al-Hazmi (2020) dealt with the determinants of applying total quality management in travel and tourism organizations in the Kingdom of Saudi Arabia and concluded that, there is a group of related barriers, infrastructure and communication outlets as well as administrative and organizational aspects in travel and tourism organizations. The study by Tartar (2019) concluded that there is a set of factors that affects the design of distribution outlets for economic organizations, represented by the organizational side, bylaws, regulations and financial resources available in economic organizations. Muhammad (2017) investigated the expansion of determinants of electronic distribution outlets in banking services and concluded that there is a set of restrictions related to the structure of the communications and software network as well as the bylaws and regulations that govern the provision of banking services to beneficiaries. While the study by Al-Khatib (2015) examined the reality of using distribution outlets in banks and emphasized on the need for diversification in the use of these outlets and the need to use modern distribution outlets capable of reaching the beneficiaries of these services and achieving their satisfaction. Through our review of previous studies, we find that most of them dealt with the issue of marketing tourism services in general or distribution of services and did not address the electronic distribution of travel and tourism services. Thus, this study is distinguished from previous studies by the following:

- The determinants of the electronic distribution of tourism services addressed travel and tourism organizations.

- This study was conducted in Al-Kharj Governorate, Kingdom of Saudi Arabia.

Table 3

Descriptive statistics results for analyzing the determinants of the expansion in the use of electronic distribution outlets in travel and tourism organizations.

\begin{tabular}{|c|c|c|c|c|}
\hline No. & Variable & Mean & Sd. Deviation & Sig. \\
\hline 1 & The bylaws and regulations govern travel and tourism organizations & 3.421 & 1.023 & 0.721 \\
\hline 2 & Centralized management in planning and decision-making & 3.245 & 0.816 & 0.705 \\
\hline 3 & Weak interest in research and development in travel and tourism organizations & 3.620 & 1.231 & 0.789 \\
\hline 4 & Poor financial capabilities & 3.061 & 0.819 & 0.614 \\
\hline 5 & Lack of human expertise to manage electronic distribution outlets & 3.321 & 1.002 & 0.690 \\
\hline 6 & Lack of necessary software for the work of electronic distribution outlets & 3.109 & 0.989 & 0.701 \\
\hline 7 & Poor performance of the communications network & 3.541 & 1.121 & 0.745 \\
\hline 8 & The expected risks resulted by the use of the electronic distribution & 2.987 & 0.765 & 0.605 \\
\hline 9 & Poor customers' awareness of the importance of electronic distribution outlets & 4.438 & 1.867 & 0.832 \\
\hline Total & & 3.425 & 1.156 & 0.731 \\
\hline
\end{tabular}

* (1 - less than 2.8) weak, (2.8 - less than 3.6) medium, (3.6-5) high

From the previous table, we find that the total of the arithmetic mean of the determinants of expansion in the use of electronic distribution outlets in travel and tourism organizations reached $(3,425)$ with a standard deviation $(1.156)$. This indicates that there is a group of determinants which limit the use of electronic distribution outlets by travel and tourism organizations in the Kingdom of Saudi Arabia, and we find that paragraph No. 9 related to the determinant of poor customers' knowledge of the importance of electronic distribution outlets for travel and tourism services where the average arithmetic value reached $(4,438)$ with a deviation Standard (1.867). This indicates a lack of awareness among customers of tourism organizations of the importance of using electronic distribution outlets. Paragraph No. 8 regarding the expected risks as a result of using electronic distribution outlets in the distribution of tourism services got the lowest average arithmetic value (2.987) with a standard deviation of (1.156). This indicates the expected risks as a result of the use of electronic distribution outlets by tourism and travel organizations. It affects the nature of the use of these outlets and limits their use.

Table 4

Results of the study hypothesis test.

\begin{tabular}{|c|c|c|c|c|c|c|}
\hline \multirow{2}{*}{ No. } & \multirow{2}{*}{ Variable } & \multicolumn{5}{|c|}{ Test Value $=3$} \\
\hline & & Mean & Sd. Dev. & $\mathbf{t}$ & df & Sig. (2-tailed) \\
\hline 1 & The bylaws and regulations governing travel and tourism organizations & 3.421 & 1.023 & 11.564 & 112 & 0.000 \\
\hline 2 & Centralized management planning and decision-making & 3.245 & 0.816 & 11.273 & 112 & 0.000 \\
\hline 3 & Weak interest in research and development in travel and tourism organizations & 3.620 & 1.231 & 11.887 & 112 & 0.000 \\
\hline 4 & Poor financial capabilities & 3.061 & 0.819 & 10.987 & 112 & 0.000 \\
\hline 5 & The lack of human expertise to manage electronic distribution outlets & 3.321 & 1.002 & 11.376 & 112 & 0.000 \\
\hline 6 & The lack of software necessary for the work of electronic distribution outlets & 3.109 & 0.989 & 11.298 & 112 & 0.000 \\
\hline 7 & Poor performance of the communications network & 3.541 & 1.121 & 11.679 & 112 & 0.000 \\
\hline 8 & The expected risks resulted from the use of the electronic distribution & 2.987 & 0.765 & 10.561 & 112 & 0.000 \\
\hline 9 & Poor customers' awareness of the importance of electronic distribution outlets & 4.438 & 1.867 & 12.326 & 112 & 0.000 \\
\hline
\end{tabular}

* (1 - less than 2.8) weak, (2.8 - less than 3.6) medium, (3.6-5) high 
From Table 4, which shows the results of the study hypothesis test, we find the following:

- The average value of an axis for the bylaws and regulations governing work in tourist facilities was (3.421), which is a value that falls within the approval range and a standard deviation of (1.023) and the calculated value ( $\mathrm{t})$ is (11.564), which is a function at the level of significance $(0,000)$ with a confidence degree above $99 \%$. This means the validity of the hypothesis that: There is a statistically significant relationship at the level of significance $(\alpha \leq 0.05)$ between bylaws and regulations that govern travel and tourism organizations and electronic distribution outlets for tourism services. We reject the unacceptable hypothesis: There is no statistically significant relationship at the level of significance $(\alpha \leq 0.05)$ between bylaws and regulations that govern travel and tourism organizations and electronic distribution outlets for tourism services.

- The average value of an axis for the bylaws and regulations governing work in tourist facilities reached (3.421), which is a value that falls within the approval range with a standard deviation of (1.023) and the calculated value (t) is (11.564), which is a function at the level of significance $(0,000)$ with a confidence degree above $99 \%$. This means the validity of the hypothesis that: There is a statistically significant relationship at the level of significance $(\alpha \leq 0.05)$ between bylaws and regulations that govern travel and tourism organizations and electronic distribution outlets for tourism services. We reject the unacceptable hypothesis: There is no statistically significant relationship at the level of significance $(\alpha \leq 0.05)$ between bylaws and regulations that govern travel and tourism organizations and electronic distribution outlets for tourism services.

- The average value of the axis of weak awareness of research and development in tourism organizations reached (3.620), which is a value that falls within the approval range with a standard deviation of (1.231) and the calculated value of $(\mathrm{t})$ is (11.887), which is a function at the level of significance (0.000) with a confidence level above $99 \%$. This means the validity of the hypothesis that there is a statistically significant relationship at the level of significance $(\alpha \leq 0.05)$ between interest in research and development in travel and tourism organizations and electronic distribution outlets for tourism services. We reject the unacceptable hypothesis: There is no statistically significant relationship at the significance level $(\alpha \leq 0.05)$ between interest in research and development in travel and tourism organizations and electronic distribution outlets for tourism services.

- The average value of the resource axis financial capabilities in tourism organizations reached (3.061), which is a value that falls within the approval range with a standard deviation of $(0.819)$ and the calculated value $(t)$ is $(10.987)$, which is a function at the level of significance $(0.000)$ with a confidence level above $99 \%$. This means the validity of the hypothesis that: There is a statistically significant relationship at the level of significance $(\alpha \leq 0.05)$ between the financial capabilities of travel and tourism organizations and the electronic distribution outlets for tourism services. We reject the unacceptable hypothesis: There is no statistically significant relationship at the significance level $(\alpha \leq 0.05)$ between the financial capabilities of travel and tourism organizations and the electronic distribution outlets for tourism services.

- The average value of the axis of human experiences in managing the electronic distribution outlets present in tourist organizations reached (3.321), which is a value that falls within the approval range with a standard deviation of (0.819) and the calculated value of $(\mathrm{t})$ is $(11.376)$ which is a function at the level of significance $(0,000)$ with a higher confidence level from $99 \%$. This means the validity of the hypothesis that, there is a statistically significant relationship at the level of significance $(\alpha \leq 0.05)$ between the human experiences required for managing electronic distribution in travel and tourism organizations and electronic distribution outlets for tourism services. We reject the unacceptable hypothesis: There is no statistically significant relationship at the significance level $(\alpha \leq 0.05)$ between the human experiences required for managing electronic distribution in travel and tourism organizations and electronic distribution outlets for tourism services.

- The average value of the axis of software for distribution outlets management software in tourist organizations reached (3.109), that is a value which falls within the approval range with a standard deviation of (0.989) and the calculated value of ( $\mathrm{t})(11.298)$, which is a function at the level of significance $(0.000)$ with a confidence level above $99 \%$. This means the validity of the hypothesis: There is a statistically significant relationship at the significance level $(\alpha \leq 0.05)$ between the management programs of distribution outlets available in travel and tourism organizations and electronic distribution outlets for tourism services and we reject the unacceptable hypothesis: There is no statistically significant relationship at the level of significance $(\alpha \leq 0.05)$ between the software for managing the distribution outlets available in travel and tourism organizations and the electronic distribution outlets for tourism services.

- The average value of the axis of performance of electronic communication networks in tourism organizations reached (3.541), which is a value that falls within the approval range with a standard deviation of (1.121) and the calculated value of $(t)$ is (11.679), which is a function at the level of significance $(0.000)$ with a confidence level above $99 \%$. This means the validity of the hypothesis: There is a statistically significant relationship at the level of significance $(\alpha \leq 0.05)$ between the performance of electronic communication networks in travel and tourism organizations and the electronic distribution outlets for tourism services. We reject the unacceptable hypothesis: There is no statistically significant relationship at the significance level $(\alpha \leq 0.05)$ between the performance of electronic communication networks in travel and tourism organizations and the electronic distribution outlets for tourism services.

- The average value of the risk axis of the electronic distribution of travel and tourism organizations reached (2.987), which is a value that falls within the approval range with a standard deviation of $(0.765)$ and the calculated value of (t) is (10.561), which is a function at the level of significance $(0,000)$ with a confidence degree above $99 \%$. This means the validity of the hypothesis: There is a statistically significant relationship at the level of significance $(\alpha \leq 0.05)$ between the risks of electronic distribution to travel and tourism organizations and electronic distribution outlets for tourism services. We 
reject the unacceptable hypothesis: There is no statistically significant relationship at the significance level $(\alpha \leq 0.05)$ between the risks of the electronic distribution of travel and tourism organizations and the electronic distribution outlets of tourism services.

- The average value of the axis of awareness of customers of travel and tourism organizations of the importance of electronic distribution outlets reached $(4,438)$, which is a value that falls within the approval range with a standard deviation of (1.867) and the calculated value of $(t)$ is (12.326) which is a function at the level of significance $(0.000)$ with a confidence level above $99 \%$. This means the validity of the hypothesis: There is a statistically significant relationship at the level of significance $(\alpha \leq 0.05)$ between the customers' awareness of travel and tourism organizations on the importance of electronic distribution outlets and electronic distribution outlets for tourism services. We reject the unacceptable hypothesis: There is no statistically significant relationship at the significance level $(\alpha \leq 0.05)$ between the customers' awareness of travel and tourism organizations on the importance of electronic distribution outlets and electronic distribution outlets for tourism services.

\section{Conclusion}

Through our review of the results of the study hypotheses test, we find that there is a set of factors that limits and affects the use of electronic distribution outlets in the distribution of travel and tourism services. The availability of the trained human element who are capable to use the electronic distribution outlets for tourism services, as well as the customers' awareness of the importance of these means plays a major role in their use and taking the risk in switching to electronic distribution methods. Accordingly, travel and tourism organizations in Al-Kharj Governorate should work to use highly efficient and effective communication networks and work to develop systems and bylaws governing tourism work and to follow decentralized and typical methods in the planning and decision-making process through administrative restructuring and defining the scope of administrative supervision and work to develop the electronic infrastructure through the use of advanced systems and software capable of keeping pace with the development in customers' orientations and desires and the orientation towards the use of electronic systems in the processes of distributing their services. As well as working to attract qualified technical cadres who are capable to use modern methods in the distribution of tourism services and work to raise the level of customers' awareness of the importance of electronic distribution by providing a marketing matrix capable of attracting customers and improving and developing their mental image about the services of travel and tourism organizations in Al-Kharj Governorate in the Kingdom of Saudi Arabia Saudi.

\section{References}

Al-Hazmi, N. (2020a). The impact of information technology on the design of distribution channels. Uncertain Supply Chain Management, 8(3), 505-512.

AL-hazmi, N \& Hassan, Y. (2020). Barriers on marketing tourism services and their impacts on customer awareness. Management Science Letters, 10(11), 2603-2608.

AL-hazmi, N. (2020b). The impact of market targeting strategies on tourism services. Management Science Letters, 10(12), 2799-2804.

AL-Hazmi, N \& Alkhateeb, T. (2020). Obstacles to implementing total quality management in Saudi Arabia marketing tourism Services.Management Science Letters, 10(3), 507-514.

Al-Hazmia, N. (2020c). A study on the dimensions of the quality of tourism services in the Kingdom of Saudi Arabia. Management Science Letters, 10(5), 1115-1120.

Alkhteeb, B. (2015). The role of two public information technology applications that do not involve commercial banking. Master Thesis, Collage of Economic, A University of Damaschatta.

Almohammed, S. (2017). Determinants of expansion in the electronic distribution channels of banking services. Aleppo University Research Journal, 65, 245-261.

Charis, C. (2015). Opening Accounts on The Web: Make It Simple. American Banker, 170(219), 14-15.

Jaddi, S. (2019). The role of distribution channels management in increasing the competitiveness of production organizations. Master Thesis, Institute of Business and Management Sciences, Pestah University.

Tertar, A. (2019). Factors affecting the design of distribution channels in economic organizations. Arabic Management Journal ,3(2), 513-525.

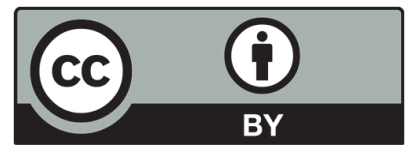

(C) 2021 by the authors; licensee Growing Science, Canada. This is an open access article distributed under the terms and conditions of the Creative Commons Attribution (CC-BY) license (http://creativecommons.org/licenses/by/4.0/). 